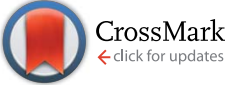

Cite this: RSC Adv., 2017, 7, 9964
Received 25th September 2016 Accepted 23rd December 2016

DOI: 10.1039/c6ra23826b

www.rsc.org/advances

\section{Tunable multilayer assemblies of nanofibrous composite mats as permeable protective materials against chemical warfare agents $\uparrow$}

\author{
S.-Y. Ryu, ${ }^{a}$ J. W. Chung ${ }^{\star b}$ and S.-Y. Kwak ${ }^{\star a}$
}

Lightweight nanofibrous assemblies with high protection ability against chemical warfare agents (CWAs) were developed using laminated outer and inner layers based on nanofibre composites. The outer layer was composed of a meta-aramid nanofibre and CWA adsorbents ( $\mathrm{MgO}$ and POM), and possessed high mechanical strength and an amphiphobic surface capable of repelling liquid CWAs. The inner layer, consisted of a polyamide 66 nanofibre and CWA adsorbents, exhibited low permeability to gas CWAs and high permeability to water vapor. These outer and inner layers were prepared by simultaneous electrospinning and electrospraying processes. By controlling the stacking of the inner and outer layers, the characteristics of their assemblies, such as thickness, weight density, and cool/warm feeling, were improved. In addition, the assemblies resisted the invasion of CWAs, while still maintaining considerable water vapor transmission to allow evaporative cooling of the wearer. Based on these results, assemblies composed of nanofibrous composite can be used as in garments that protect wearers from various contaminants such as organic pollutants and harmful particulates, as well as from CWAs.

\section{Introduction}

Chemical warfare agents (CWAs) have been used in tactical warfare as incendiary mixtures, smoke, and irritating, burning, poisonous, or asphyxiating gases. ${ }^{1}$ CWAs have been classified according to their target organs or tissues as nerve, vesicant, choking, blood and vomiting agents, as well as incapacitants and lacrimators. ${ }^{2}$ Many CWAs are dermally active; therefore, a number of studies on materials that provide protection against CWAs have been performed. ${ }^{3-5}$ There are various types of defense equipment available to protect the body from CWAs, including detectors, respirators, protective clothing, decontaminants and medical counter measures. ${ }^{6}$ Protective clothing

${ }^{a}$ Department of Materials Science and Engineering, Seoul National University, 1 Gwanak-ro, Gwanak-gu, Seoul 08826, Korea. E-mail: sykwak@snu.ac.kr; Fax: +82-2885-9671; Tel: +82-2-880-8365

${ }^{b}$ Department of Organic Materials and Fibre Engineering, Soongsil University, 369 Sangdo-ro, Dongjak-gu, Seoul 06978, Korea. E-mail: jwchung@ssu.ac.kr; Fax: +82-2817-8346; Tel: +82-2-828-7047

$\dagger$ Electronic supplementary information (ESI) available: Mechanical properties of pristine polyamide 66 nanofibre and composite nanofibre mats for inner layer; schematic representation of the simultaneous electrospinning and electrospraying process; DSC curves of meta-aramid nanofibre; schematic representations of the permeation experimental systems used to investigate the resistance of the nanofibre composites against gas CWA simulants and fabrication of assemblies of composite nanofibre mats; flow pore characteristics of the nanofibre mats; morphology of pristine meta-aramid and polyamide 66 nanofibres; EDS mapping image of nanofibre composites for outer layer; penetration behavior of CWA simulants through assemblies. See DOI: 10.1039/c6ra23826b can be classified into impermeable and permeable categories. Impermeable protective clothing offers powerful protection against CWAs, but is unfit for long-term wear because it is cumbersome and uncomfortable. In contrast, permeable protective clothing is composed of outer and inner layers to make it breathable. The outer layer repels the liquid CWA that is trying to penetrate the protective clothing. The inner layer consists of nonwoven fabric or porous foam impregnated with an adsorbent, such as activated carbon, to chemisorb any gas CWA that enters through the outer layer.

The activated carbon materials used in permeable protective clothing is impregnated with nanoparticles composed of silver, tin, zinc or molybdenum, along with triethylenediamine. A popular example of a permeable protective garment containing activated carbon materials is the joint service lightweight integrated suit technology (JSLIST) overgarment, which has been used by the US Army. ${ }^{7}$ Permeable protective clothing like the JSLIST suit offers complete protection against CWAs, but it has associated disadvantages such as moisture retention and heavy weight (2.63 kg per overgarment), resulting in discomfort. These disadvantages prevent users from wearing JSLIST suits for more than 6-8 $\mathrm{h}$ at a time. Therefore, there is a need to develop a more comfortable clothing that is light, with high moisture permeability, but that still protects the wearer from CWAs.

A number of protective materials with higher adsorption capacity, lighter weight and greater comfort than their predecessors have been designed. Catalysts and adsorbents with detoxification activity such as $\mathrm{MgO},{ }^{8,9} \mathrm{MnO}_{2},{ }^{10} \mathrm{ZnO},{ }^{11,12} \mathrm{TiO}_{2},{ }^{13}$ $\mathrm{ZnTiO}_{3},{ }^{14} \mathrm{M} / \mathrm{TiO}_{2} / \mathrm{SiO}_{2}\left(\mathrm{M}=\mathrm{Fe}, \mathrm{Mn}\right.$, and V), ${ }^{15} \mathrm{WO}_{3} /$ titanate, ${ }^{16} \mathrm{~N}$ - 
doped $\mathrm{TiO}_{2},{ }^{17} \mathrm{Au} / \mathrm{TiO}_{2},{ }^{18}$ and polyoxometalate $(\mathrm{POM})^{19}$ have been actively investigated as the fillers incorporated in such permeable protective clothing. Among these fillers, $\mathrm{MgO}$ has been widely studied as an effective catalyst against the sarin, nerve agent, because it is highly active and can readily decompose this nerve agent. ${ }^{20} \mathrm{MgO}$ can physisorb CWAs on its surface through the formation of hydrogen-bonding, ion-dipole and dipole-dipole interactions. ${ }^{21}$ In addition, POM has been considered as a reactive and recoverable catalyst for the decontamination of vesicant agents such as sulfur mustard (HD)..$^{22,23}$

The disadvantages of existing permeable protective clothing can be overcome by replacement with lightweight materials composed of structures such as nanofibres. Nanofibres, like all other electrospun nanostructures, ${ }^{24-26}$ show improved properties compared with those of conventional fibres because of their small dimensions and unique features, such as high surface-tovolume ratio, small fibre-to-fibre distance, high porosity, large specific surface area, small pore size, and high controllability. These unique characteristics, plus the functionalities of the materials themselves, impart nanofibres with a number of novel properties that are attractive for advanced applications. Nanofibres have been used in protective clothing for CWAs, as well as for biological warfare agents. Various methods to modify nanofibre surfaces to enhance their protection and decontamination capabilities have been developed based on chemical surface modification and attachment of reactive groups on the nanofibre surface, and especially functionalized nanofibres for protection from chemical warfare simulants based on hydrolysis have been developed and evaluated. ${ }^{27}$ In addition, catalysts, such as $\mathrm{MgO}$ and POM, were incorporated into nanofibres, and the resulting nanofibre-bound catalysts decontaminated CWAs., ${ }^{\mathbf{8} 28}$

Herein, we demonstrate a potential application of nanofibrous composite materials impregnated with $\mathrm{MgO}$ and POM adsorbents as the inner and outer layers, respectively, of permeable materials that are protective against CWAs. The inner and outer layers of the composite nanofibre mats are stacked on one another to assemble protective clothing materials. The outer layer consists of both meta-aramid nanofibres and the absorbents and has an amphiphobic nature, so the liquid CWA simulants bounce off it. The inner layer is composed of Nylon 66 nanofibres with $\mathrm{MgO}$ and POM as absorbents, and plays a role in protection by adsorbing gas CWA simulants. The assembly of these two layers improved the thickness, weight, water vapor transmittance, cool/warm feeling and protection against CWA simulants compared with the corresponding properties of existing permeable protective clothing materials. In particular, the thickness and weight density of the material depended on the number of stacked layers. Lightweight assemblies with high protection against CWAs were developed. These assemblies provide good resistance to the penetration of gaseous CWAs, while still allowing water vapor transmission to promote evaporation cooling of the wearer. The assembly of multiple layers developed here reveals a new approach to improve the performance of permeable protective materials, and will aid the design and optimization of permeable protective clothing.

\section{Experimental}

\section{Materials}

Commercial $\mathrm{MgO}$ (light and heavy grade), POM (ammonium (para)tungstate hydrate, $\left(\mathrm{NH}_{4}\right)_{10}\left(\mathrm{H}_{2} \mathrm{~W}_{12} \mathrm{O}_{42}\right) \cdot 4 \mathrm{H}_{2} \mathrm{O}$, and ammonium phosphomolybdate hydrate, $\left.\left(\mathrm{NH}_{4}\right)_{3} \mathrm{PMo}_{12} \mathrm{O}_{40} \cdot n \mathrm{H}_{2} \mathrm{O}\right)$ as absorbents of the chemical warfare agent (CWA) simulants were purchased from various manufacturers, as listed in Table 1. All samples were stored under ambient conditions before adsorption testing. 2-Chloroethyl ethyl sulfide (2-CEES; 98\% GC purity) and dimethyl methylphosphonate (DMMP, 97\% GC purity) were purchased from Sigma-Aldrich (USA) as CWA simulants of mustard gas and sarin, respectively. All materials were used as received without further purification. Poly(meta-phenylene isophthalamide) (meta-aramid, Nomex, DuPont, USA), $\mathrm{N}, \mathrm{N}$-dimethylacetamide (DMAc, anhydrous, 99.8\%, Sigma-Aldrich, USA), lithium chloride (LiCl, ACS reagent, $\geq 99 \%$, Sigma-Aldrich, USA), Unidyne TG-5601 (water-based emulsion; $20-30 \%$ fluoroalkyl acrylate copolymer, 5\% poly(oxyethylene) alkyl (C12-14) ether, $1-10 \%$ tripropylene glycol, 55-65\% water and 5\% other materials; weak cation; as water and oil repellent, Daikin, Japan) were used as received without further purification. Poly(hexamethylene adipamide) (polyamide 66, Nylon 66, SigmaAldrich, USA), formic acid ( $\geq 95 \%$, Sigma-Aldrich, USA) and benzyltrimethylammonium chloride (BTMAC, $\geq 99.0 \%$, Tokyo Chemical Industry, Japan) were used as received without further purification.

\section{Adsorptivity of CWA simulants on MgO and POM particles}

The adsorption of the simulants on the adsorbents ( $\mathrm{MgO}$ and POM) was measured according to ASTM D5160-95. ${ }^{29}$ To produce the gas of CWA simulants, 2-CEES ( $1 \mathrm{~mL}$; vapor pressure of $<3.4$ $\mathrm{mmHg}$ at $25^{\circ} \mathrm{C}$ and volatility of $16570 \mathrm{mg} \mathrm{m}^{-3}$ of at $20^{\circ} \mathrm{C}$ ) was added to ethanol $(199 \mathrm{~mL})$, and of DMMP (10 mL; vapor pressure of $1 \mathrm{mmHg}$ at $25{ }^{\circ} \mathrm{C}$ and volatility of $347 \mathrm{mg} \mathrm{m}^{-3}$ at $20^{\circ} \mathrm{C}$ ) was added to ethanol (190 mL). Then $200 \mathrm{~mL}$ of each CWA simulant/ethanol solution was put in a bubbler and placed in a water bath at a temperature of $74 \pm 1{ }^{\circ} \mathrm{C}$. This action was performed to ensure that the simulant gas was formed effectively in the tubing and maintained at the same temperature. The adsorbent (500 mg) was fixed in a cylindrical sample chamber with $10 \mathrm{~mm}$ radius, and the adsorption temperature was controlled at $35{ }^{\circ} \mathrm{C}$. Simulant solution $(1 \% \mathrm{v} / \mathrm{v}$ in ethanol) was purged with dry $\mathrm{N}_{2}$ gas, so that the adsorbate vapor was generated continuously, and the vapor was passed through the absorbent at a flow rate of $50 \mathrm{~cm}^{3}$ for $40 \mathrm{~min}$. The expelled gas was trapped in a Tenax-TA tube, and desorption of the simulants trapped in the Tenax-TA tube was conducted using thermal desorption gas chromatograph mass spectrometry (TDS-GC-MS, GC: 6890N, Agilent; MSD: 5975, Agilent; TDS: TDS2, Gerstel). The types of $\mathrm{MgO}$ and POM showing the best performance $\mathrm{MgO}$ and POM were finally selected as adsorbents. These adsorbents were doped in polymeric nanofibres to form the inner and outer layers of protective materials using the simultaneous electrospinning and electrospraying (SEE) process. 
Table 1 Adsorptivity of chemical warfare agent simulants 2-CEES and DMMP by MgO and POM particles

\begin{tabular}{|c|c|c|c|c|c|c|c|}
\hline \multirow{2}{*}{$\begin{array}{l}\text { Manufacturer } \\
\mathrm{MgO}\end{array}$} & \multicolumn{2}{|c|}{ Sigma Aldrich } & \multicolumn{2}{|l|}{ Daejung } & \multicolumn{2}{|l|}{ Junsei } & \multirow{2}{*}{$\frac{\text { Wako }}{\text { Light }}$} \\
\hline & -325 mesh & $<50 \mathrm{~nm}$ & Light & Heavy & Light & Heavy & \\
\hline DMMP adsorptivity, $\left(\mu \mathrm{g}^{-1},(\%)\right)$ & $0.93,(78.3)$ & $0.82,(68.5)$ & $0.64,(53.4)$ & $0.61,(51.2)$ & $0.78,(65.6)$ & $0.47,(39.3)$ & $0.54,(45.6)$ \\
\hline Suitable for electrospraying & Yes & Yes & Yes & Yes & Yes & Yes & Yes \\
\hline Manufacturer & & \multicolumn{2}{|c|}{ Sigma Aldrich } & & \multicolumn{2}{|l|}{ Daejung } & Kanto \\
\hline 2-CEES adsorptivity $\left(\mu \mathrm{g} \mathrm{g}^{-1},(\%)\right)$ & & \multicolumn{3}{|l|}{$0.61,(79.8)$} & \multicolumn{2}{|l|}{$0.57,(74.0)$} & $0.72,(93.7)$ \\
\hline DMMP adsorptivity $\left(\mu \mathrm{g} \mathrm{g}^{-1},(\%)\right)$ & & \multicolumn{3}{|l|}{$0.72,(60.7)$} & \multicolumn{2}{|l|}{$0.79,(66.4)$} & $0.87,(73.0)$ \\
\hline Suitable for electrospraying & & \multicolumn{3}{|l|}{ No } & \multicolumn{2}{|l|}{ Yes } & Yes \\
\hline
\end{tabular}

\section{Nanofibrous outer layer for repellent protection against CWA simulants}

The composite nanofibre for the outer layer consisting of metaaramid nanofibre ( $m \mathrm{ANF}$ ) and selected absorbent ( $\mathrm{MgO}$ or POM) was prepared using the SEE process ${ }^{30}$ (Fig. S1 $\dagger$ ). The SEE apparatus was constructed with a rotating drum collector, two positive DC voltage supplies, one negative DC voltage supply, and two syringe pumps composed of housings with syringe retainers. These syringe pumps were placed on opposite sides to the collector. To prepare the electrospinning solution of $m$ ANF, Nomex fibre $(8 \mathrm{~g})$ was dissolved in DMAc solution $(50 \mathrm{~mL})$ containing $\mathrm{LiCl}(1.6 \mathrm{~g})$ as a salt $(1: 5$ weight ratio of LiCl/Nomex $)$ at $50{ }^{\circ} \mathrm{C}$ for $24 \mathrm{~h}$ in an oven shaker (BF-30SI, BioFree, Korea). Pristine $m$ ANF was prepared by electrospinning as follows. A syringe with a stainless-steel needle with an internal diameter of $0.33 \mathrm{~mm}$ was filled with the electrospinning solution, which was then ejected at a flow rate of $0.15 \mathrm{~mL} \mathrm{~h}^{-1}$ for $68 \mathrm{~h}$. The needle tip of the syringe was directly charged at $20-25 \mathrm{kV}$. The syringe was positioned horizontally with a tip-to-collector distance of $15 \mathrm{~cm}$ from a drum collector covered with $\mathrm{Al}$ foil rotating at $100 \mathrm{rpm}$. The collector was charged at $-5 \mathrm{kV}$. The electrospinning process was conducted at $23 \pm 1{ }^{\circ} \mathrm{C}$ and $45 \pm 5 \mathrm{RH} \%$. To introduce the adsorbents on the surface of $m \mathrm{ANF}, \mathrm{MgO}$ or POM $(1 \mathrm{~g})$ was dispersed in methanol $(100 \mathrm{~mL})$ using a horn-type ultrasonicator (VCX-750, Sonics \& Materials, CT, USA) for $30 \mathrm{~min}$. Each dispersion was electrosprayed using a stainlesssteel spinneret with an internal diameter of $0.51 \mathrm{~mm}$, applied voltage at the spinneret of $12 \mathrm{kV}$, tip-to-collector distance of $10 \mathrm{~cm}$, and solution flow rate of $1.5 \mathrm{~mL} \mathrm{~h}^{-1}$ for $68 \mathrm{~h}$. Using this SEE process, pristine $\mathrm{MgO} / \mathrm{mANF}$ and $\mathrm{POM} / \mathrm{mANF}$ samples with a thickness of $75 \mu \mathrm{m}$ were prepared.

The as-prepared $\mathrm{MgO} / m \mathrm{ANF}$ and $\mathrm{POM} / m \mathrm{ANF}$ samples were fixed in stainless-steel frames for post-treatment. The samples were soaked in deionized water and gently shaken for $1 \mathrm{~h}$ to remove the LiCl salt and any unbound adsorbents from the nanofibres. The samples were heat-treated in air at $300^{\circ} \mathrm{C}$ (above the glass transition temperature of a neat Nomex nanofibre, see Fig. S2 $\dagger$ ) for $10 \mathrm{~min}$ in a processing oven (UF 110, Memmert, Germany) to enhance their chemical stability and mechanical properties. To generate amphiphobic surfaces, the heat-treated samples were treated with Unidyne (Daikin, Osaka, Japan), which is a fluorinated water and oil repellent. The samples were immersed in Unidyne $(200 \mathrm{~mL})$ for $10 \mathrm{~min}$, and then stabilized for $10 \mathrm{~min}$ in air. The samples were transferred into the processing oven and heat treated at $180{ }^{\circ} \mathrm{C}$ for $3 \mathrm{~min}$ to give composite nanofibre mats with amphiphobic surfaces (denoted $[\mathrm{O}] \mathrm{MgO} / \mathrm{mANF}$ and $[\mathrm{O}] \mathrm{POM} / \mathrm{mANF}$ ) for use as outer layers.

The surface morphology of $[\mathrm{O}] \mathrm{MgO} / \mathrm{mANF}$ and $[\mathrm{O}] \mathrm{POM} /$ mANF was observed by field-emission scanning electron microscopy (FE-SEM, JSM-6335F; JEOL). The adsorbent content and thermal behavior of the composites was observed by simultaneous differential thermal analysis/thermal gravimetric analysis (DTA/TGA; SDT 2960; TA Instruments) using a heating rate of $10{ }^{\circ} \mathrm{C} \min ^{-1}$, temperature range of $40-700{ }^{\circ} \mathrm{C}$, and $\mathrm{N}_{2}$ atmosphere. The repellency of the CWA simulants by each composite was determined by measurement of their static water contact angle (WCA) and oil contact angle (OCA). WCAs and OCAs were determined by contact angle measurements (Theta Lite; Attension; KSV Instruments) with a manually controlled Hamilton syringe. Apparent contact angles of water and simulant drops were measured in air at $25 \pm 1{ }^{\circ} \mathrm{C}$. A droplet with a volume of $3.0 \pm 0.2 \mu \mathrm{L}$ was formed on the surface of each nanofibre mat and droplet size was observed. Average WCAs and OCAs for results obtained at five different positions on each sample are reported, with standard deviations of $\pm 2^{\circ}$.

\section{Nanofibrous inner layer for adsorptive protection against CWA simulants}

The composite nanofibres for the inner layer consisting of polyamide 66 nanofibres (PANF) and the selected adsorbents (MgO or POM) were also prepared by the SEE process. To electrospin PANF, first polyamide 66 pellets $(5.4 \mathrm{~g})$ were dissolved in of formic acid solution $(36 \mathrm{~mL})$ containing BTMAC $(0.54 \mathrm{~g})$ as a salt and gently shaken for $24 \mathrm{~h}$ at room temperature until the solution was transparent. The solution was electrospun using a stainless-steel spinneret with an internal diameter of 0.33 $\mathrm{mm}$, applied voltages of $18-20 \mathrm{kV}$ at the spinneret and $-5 \mathrm{kV}$ at the collector, a tip-to-collector distance of $9 \mathrm{~cm}$, collector 
rotation speed of $100 \mathrm{rpm}$, and solution flow rate of $1.0 \mathrm{~mL} \mathrm{~h}^{-1}$ for $10 \mathrm{~h}$ at $22 \pm 1{ }^{\circ} \mathrm{C}$ and $50 \pm 5 \% \mathrm{RH}$. To introduce the adsorbents on the surface of PANF, absorbent ( $1 \mathrm{~g})$ was dispersed in methanol (100 mL) using a horn-type ultrasonicator (VCX-750, Sonics \& Materials, CT, USA) for $30 \mathrm{~min}$. The dispersion was electrosprayed using a stainless-steel spinneret with an internal diameter of $0.51 \mathrm{~mm}$, applied voltage of $12 \mathrm{kV}$ at the spinneret, tip-to-collector distance of $10 \mathrm{~cm}$, and solution flow rate of $10.0 \mathrm{~mL} \mathrm{~h}^{-1}$ for $10 \mathrm{~h}$. The as-prepared samples were annealed at $80{ }^{\circ} \mathrm{C}$ for $30 \mathrm{~min}$ in a processing oven (UF 110, Memmert, Germany) to adhere the adsorbents on the surface of the nanofibres. The samples were washed four times with deionized water/methanol solution to remove the salt and any unbound absorbents from the nanofibres. Washed samples were dried at room temperature for 1 day in air and a vacuum oven, and stored in a vacuum desiccator. This process gave composite nanofibre mats (denoted [I]MgO/PANF and [I] $\mathrm{POM} / \mathrm{PANF}$ ) with a thickness of $91 \mu \mathrm{m}$ for use as inner layers to protect against gas CWAs.

The morphology of the composite nanofibre mats was evaluated by FE-SEM (JSM-6335F; JEOL). The adsorbent content of the composites was determined by thermogravimetric analysis (TGA; Q5000 IR, TA Instruments) using a heating rate of $10{ }^{\circ} \mathrm{C}$ $\min ^{-1}$, temperature range of $40-600{ }^{\circ} \mathrm{C}$, and $\mathrm{N}_{2}$ atmosphere. The mechanical properties of the nanofibre mats were measured with a universal testing machine (UTM, Model 5567; INSTRON). Specimens with a width of $3.00 \mathrm{~mm}$ and thickness of 0.10-0.20 mm were prepared according to ASTM D638 Type V. The flow pore diameter and distribution of the nanofibre mats were measured with a capillary flow porometer (CFP-1500AEL; Porous Material Inc., USA) using SilWick silicone fluid (Porous Materials Inc.) with a surface tension of 19.1 dynes $\mathrm{cm}^{-1}$ as the wetting agent for porometry measurements. Air (0100 psi) was used as a working gas. The air permeability of the nanofibre mats was measured according to the ASTM D737 standard. The water vapor transmission rate (WVTR) of the nanofibre mats was evaluated using the ASTM E96 standard. The permeation of gas CWA simulants (2-CEES and DMMP) through the nanofibre mats was determined by direct contact and dynamic diffusion permeation experiments according to a modified ASTM F739 standard, as illustrated in Fig. S3. $\dagger$ In the case of a direct contact experiment, $\mathrm{N}_{2}$ gas with a flow rate of 50 $\mathrm{cm}^{3} \min ^{-1}\left(50 \mathrm{~mL} \mathrm{~min}^{-1}\right.$ ), which was regulated using a flow meter (MKP, MPR-3000 s), delivered gas CWA simulants to the PANF mats for $20 \mathrm{~min}$. Then, the simulant gas $\left(1000 \mathrm{~cm}^{3}\right)$ was passed through the mats (area of $4.9 \mathrm{~cm}^{2}$ and thickness of 180 $\mu \mathrm{m})$ and collected by the Tenax-TA tube. The captured gas was evaluated by thermal desorption gas chromatography-mass spectrometry (TD-GC-MS). The equipment required for TDGC-MS was connected to the setup with Teflon and Tygon tubing. In the case of dynamic diffusion experiments, the simulant gas was passed over the upper surface of a nanofibre mat along an upstream line at a flow rate of $50 \mathrm{~cm}^{3}$. At the same time, $\mathrm{N}_{2}$ carrier gas at a flow rate of $50 \mathrm{~cm}^{3}$ travelled along a downstream line, delivering the simulant gas that passed through the nanofibre mat (area of $25.5 \mathrm{~cm}^{2}$ and thickness of
$180 \mu \mathrm{m})$ to the Tenax-TA tube for $40 \mathrm{~min}$. The captured gas $\left(2000 \mathrm{~cm}^{3}\right)$ was evaluated by TD-GC-MS.

\section{Assembly of the outer and inner layers to form nanofibrous protective materials against CWA simulants}

To fabricate the nanofibrous protective materials, assemblies of the outer and inner layers were prepared by a spray- and heatbonding process (Fig. S4†). Multiple layers were sequentially positioned on top of one another. First, the spray glue was spread on an inner layer through a mesh to minimize the loss of available active area on its surface. Another inner layer was then placed above the adhesive surface of the bottom layer. This procedure was repeated one to seven times. The outer layers were positioned on the inner layers perpendicular to the direction of nanofibre alignment (rotated $90^{\circ}$ between adjacent layers). Finally, assemblies composed of two outer layers and two to eight inner layers were obtained by heat-pressing at $80{ }^{\circ} \mathrm{C}$ under 500 psi for 10 min using a hydraulic press (Carver, model 2702, USA).

To examine the physical characteristics of the assemblies, various characterization techniques, such as air permeability, WVTR, and maximum heat transfer rate $\left(q_{\max }\right)$, were investigated using the standard methods ASTM D737, ASTM E96, and KES-F7 Thermo LaboII, respectively. The cool/warm feeling of the assembly was examined by measuring $q_{\max }$ (ref. 31) using a Thermo Labo II (KES-F7, KATO Tech Co., Japan), the main components of which were a temperature-detecting box (T-Box) and bottom-temperature box (BT-Box). The assembly, which was maintained at $20^{\circ} \mathrm{C}$, was positioned between the T-Box and BT-Box, which were heated to $32{ }^{\circ} \mathrm{C}$ to simulate human skin. Then, $q_{\max }$ was quickly measured for $0.2 \mathrm{~s}$ from the moment of contact. The reported results are the average of five experiments. The permeation of gas CWA simulants (2-CEES and DMMP) through each assembly was determined by permeation experiments according to the TOP 8-2-501 standard, as outlined in Fig. S5. $\uparrow$ The TOP 8-2-501 test method is based on the static diffusion procedure described in the U.S. Army Test and Evaluations Command Test Operations Procedure. ${ }^{32}$ The permeation test cell was composed of a cap and a base. A circular sample was positioned on the base containing a central well with a $5.7 \mathrm{~cm}$ diameter and inlet and outlet ports connected to Tygon tubing. The liquid simulant (2-CEES or DMMP) was dropped onto the surface of the sample at a fixed ratio of $10 \mathrm{~g}$ $\mathrm{m}^{-2}$ based on sample area. A cap covered the top of the sample and simulant to limit escape of the evaporated gas simulant. The liquid simulant on the sample evaporated into the space covered by the cap, and then the gas simulant crossed through the sample. Input $\mathrm{N}_{2}$ gas that delivered gas simulant $\left(2000 \mathrm{~cm}^{3}\right)$ to the Tenax-TA tube was regulated using a flow meter (MKP, MPR-3000s) with a flow rate of $200 \mathrm{~cm}^{3}$. The captured gas was evaluated by TD-GC-MS.

\section{Results and discussion}

\section{Adsorptivity of CWA simulants on MgO and POM particles}

To select suitable adsorbents to incorporate into composite nanofibres to form nanofibrous inner layers of protective 
materials against gas CWAs, we investigated the absorptivity of seven types of commercial MgO (light and heavy grade) and three types of POM for 2-CEES and DMMP according to the ASTM D5160-95 standard. As shown in Table 1, MgO candidates

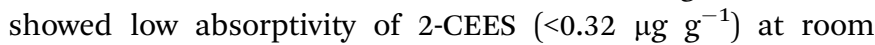
temperature, but moderate absorptivity of DMMP $(0.47-0.93 \mu \mathrm{g}$ $\mathrm{g}^{-1}$ ). In contrast, POM species ammonium (para)tungstate hydrate and ammonium phosphomolybdate hydrate showed relatively higher absorptivity of 2-CEES $\left(0.57-0.72 \mu \mathrm{g} \mathrm{g}^{-1}\right)$ and moderate absorptivity of DMMP $\left(0.72-0.87 \mu \mathrm{g} \mathrm{g}^{-1}\right)$ compared with that of $\mathrm{MgO}$ samples. In addition, we checked the processability of the $\mathrm{MgO}$ and POM particles for electrospraying. Only ammonium (para)tungstate hydrate did not disperse in solvents such as methanol for electrospraying. Other candidates dispersed well in methanol, so they could be incorporated into composite nanofibres by electrospraying. Considering both the adsorption efficiency of CWA simulants and electrospraying ability of the various $\mathrm{MgO}$ and POM candidates, we selected a fine white powder of -325 mesh from Sigma-Aldrich as $\mathrm{MgO}$ and a fine yellow powder of ammonium phosphomolybdate hydrate produced by Kanto as the POM to incorporate as adsorbents into nanofibrous protective materials against CWAs.

\section{Nanofibrous outer layer for repellent protection against CWA simulants}

We introduced the selected absorbents ( $\mathrm{MgO}$ and POM) onto the surface of mANF using the SEE process, which effectively deposited the absorbents on the surface of the nanofibres. The as-prepared $\mathrm{MgO} / m \mathrm{ANF}$ and $\mathrm{POM} / m \mathrm{ANF}$ composite nanofibre mats were washed to remove the LiCl salt, which prevented crystallization of Nomex. The composite nanofibres were then heat-treated to induce crystallization, which enhanced their chemical stability and mechanical properties. An amphiphobic outer layer was produced by post-treatment with a fluorinated water and oil repellent to give $[\mathrm{O}] \mathrm{MgO} / \mathrm{mANF}$ and $[\mathrm{O}] \mathrm{POM} / \mathrm{mANF}$.

The pristine Nomex nanofibres produced by electrospinning had a uniform diameter of $207 \pm 54 \mathrm{~nm}$ and form uniaxially aligned arrays (Fig. S6†). In the case of the nanofibre composites containing the adsorbents, $\mathrm{MgO}$ and POM were dispersed on and between the nanofibres, as illustrated in Fig. 1 and S7. $\dagger$ The alignment of the nanofibres was preserved despite the presence of the adsorbents. In addition, it is possible to change the content of the adsorbents in the composite nanofibres by regulating SEE conditions such as concentration and flow rate. To determine the thermal properties of the composite nanofibres and their adsorbent content, DTA/TGA was conducted in $\mathrm{N}_{2}$ at a heating rate of $10{ }^{\circ} \mathrm{C} \mathrm{min}{ }^{-1}$. As shown in Fig. 2, the neat Nomex nanofibres showed a dramatic weight loss around $465{ }^{\circ} \mathrm{C}$ (see the inset), and the as-prepared composite nanofibres showed similar thermal degradation behavior. The thermal behavior of the MgO- and POM-incorporated composite nanofibres was similar. The adsorbent content of the composite nanofibres was $14.1 \pm 0.5 \%$, which was calculated from the ratio of the nanofibres to adsorbent. The temperatures at $10 \%$ weight loss $\left(T_{\mathrm{d} 10}\right)$ and dramatic weight loss reveal that the surface-incorporated adsorbents did not directly

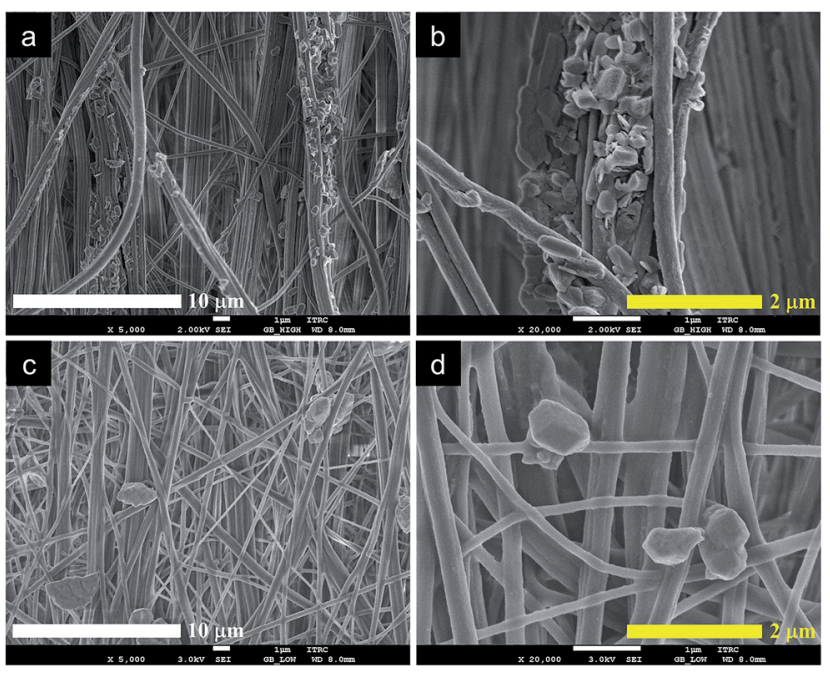

Fig. 1 Morphology of ( $a$ and b) MgO/mNAF and (c and d) POM/mANF nanofibre composites used as outer layers of nanofibrous protective materials.

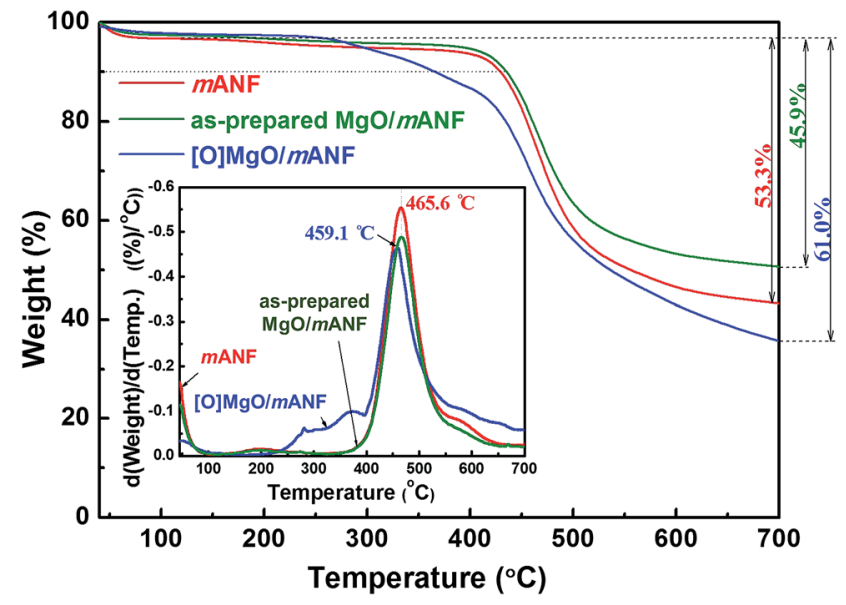

Fig. 2 Differential thermal analysis (inset) and thermal gravimetric analysis of neat $m A N F$, as-prepared $\mathrm{MgO} / \mathrm{mANF}$, and $[\mathrm{O}] \mathrm{MgO} / \mathrm{mANF}$.

affect to the thermal properties of the composite nanofibres. In contrast, the composite nanofibres treated with the fluorinated water and oil repellent $([\mathrm{O}] \mathrm{MgO} / \mathrm{mANF})$ displayed different thermal degradation behavior. [O]MgO/mANF showed progressive weight loss in the temperature range of $250-400{ }^{\circ} \mathrm{C}$. This weight loss originated from the thermal degradation of the fluorinated water and oil repellent. Comparison of the three components at $700{ }^{\circ} \mathrm{C}$ allowed us to determine that the content of repellent in $[\mathrm{O}] \mathrm{MgO} / \mathrm{mANF}$ was $15.1 \pm 0.3 \%$.

To estimate the protective performance of composite nanofibres against liquid CWAs, the surface wettability or nonwettability of the composite nanofibres was evaluated using WCA and OCA measurements with water and CWA simulants (2-CEES and DMMP), respectively. The contact angle is the angle formed between the tangent plane to the surface of the nanofibres and the tangent plane to the surface of the liquid droplet at the point of intersection, ${ }^{33}$ and reflects the wettability 
of the nanofibres. As depicted in Fig. 3, the as-prepared $\mathrm{MgO} /$ $m$ ANF quickly absorbed both water and simulants (data not shown for $m \mathrm{ANF}$ ). This indicates that the nanofibres originally have high affinity for both water and oil. In contrast, the nanofibre mats treated with fluorinated water and oil repellent exhibited an amphiphobic nature. The mANF treated with the repellent showed high hydrophobicity $\left(\mathrm{WCA}>120^{\circ}\right)$ and oleophobicity $\left(\mathrm{OCA}>90^{\circ}\right.$ ), but these properties were not strong enough to repel the CWAs effectively from the outside. The composite nanofibre mat with the adsorbents exhibited both superhydrophobicity (WCA greater than $150^{\circ}$ ) and high oleophobicity (OCA higher than $120^{\circ}$ ). We believe that the modified surface roughness of the nanofibre mats with and without adsorbents induced the difference between their non-wettable surfaces. The geometric structure of a surface has been identified as one of the most important factors that affects surface wettability ${ }^{34}$ and high surface roughness is essential to develop non-wettable surfaces. In the case of the composite nanofibre mats, the adsorbents were incorporated on the surface of the nanofibres and nanofibre mats, so the composite nanofibre mats had rougher surfaces than the pristine Nomex nanofibre mat. This increase of surface roughness enhanced the amphiphobicity of the composite nanofibre mats compared with that of the mANF.

\section{Nanofibrous inner layer for adsorptive protection against CWA simulants}

[I]MgO/PANF and [I]POM/PANF nanofibre composites were prepared as the inner layer of protective clothing using the SEE process, which effectively deposited the adsorbents $\mathrm{MgO}$ and POM onto the surface of PANF. The morphology of the nanofibres was observed by FE-SEM. The pristine PANF were disordered, and formed a continuous shape without defects that had a smooth surface with a uniform diameter of $163 \pm 21 \mathrm{~nm}$ (Fig. S8 $\dagger$ ). In contrast, [I]MgO/PANF and [I]POM/PANF contained electrosprayed $\mathrm{MgO}$ and $\mathrm{POM}$, respectively, on and

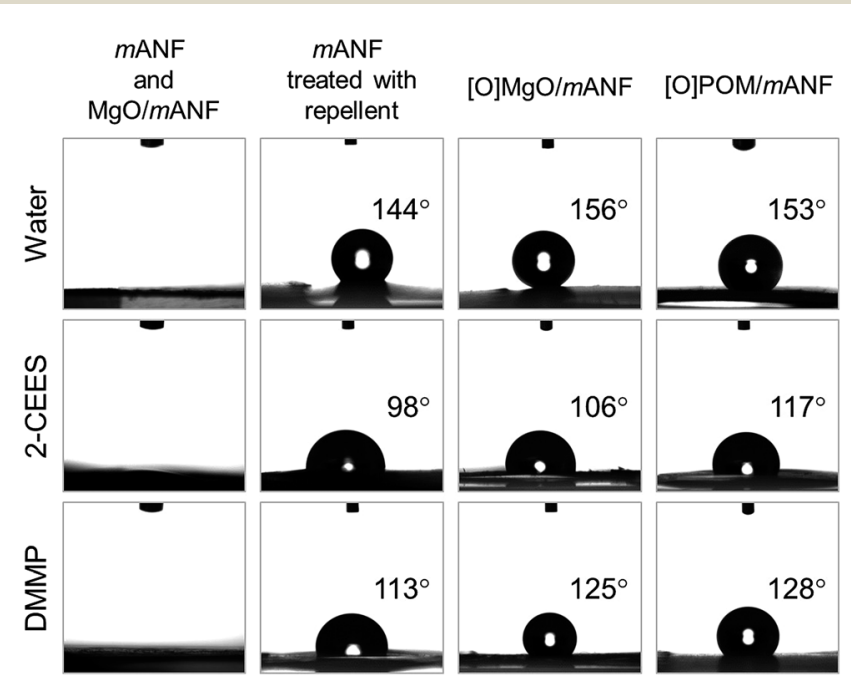

Fig. 3 Amphiphobic surface behavior of [O]MgO/mANF and [O]POM/ mANF. between the nanofibres without the formation of large aggregates, as illustrated in Fig. 4. The uniform morphology and disordered array of nanofibres was preserved despite the presence of adsorbents. The adsorbent content could be changed by controlling SEE conditions like concentration and flow rate. TGA was conducted to determine the thermal properties and absorbent contents of the composite nanofibres, as shown in Fig. 5.

Neat PANF showed a $T_{\mathrm{d} 10}$ of around $370{ }^{\circ} \mathrm{C}$ and dramatic weight loss around $400{ }^{\circ} \mathrm{C}$. [I] MgO/PANF and [I]POM/PANF, which had absorbent contents of 18.1 and $16.4 \mathrm{wt} \%$, respectively, showed similar thermal degradation behavior to that of PANF. This indicates that the adsorbents located on the surface of the nanofibres had little effect on their thermal behavior.

Tensile tests were conducted to determine the mechanical

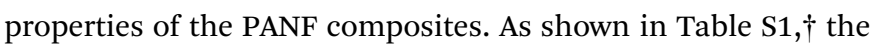
surface-incorporated adsorbents had little effect on the mechanical properties, such as the Young's modulus, tensile stress and tensile strain, of the nanofibres. The adsorbents located on the surface of the nanofibres did not improve their mechanical properties, unlike ordinary composites that contain fillers inside the nanofibres. ${ }^{35,36}$ However, the adsorbents on the nanofibre surface did affect the flow pore diameter and pore size distribution of the nanofibre mats. The pore characteristics of PANF and $[\mathrm{I}] \mathrm{MgO} / \mathrm{PANF}$ were observed by capillary flow porometry (liquid extrusion flow porometry) as shown in Fig. S9. $\dagger$ During capillary flow porometry measurements, the pores of the nanofibre mats were spontaneously filled with a wetting liquid and then the liquid was extruded from the pores by a non-reacting gas, such as $\mathrm{N}_{2}$.

The differential pressure is related to pore diameter according to $D=4 \gamma \cos \theta / p$, where $D$ is flow pore diameter, $\gamma$ is the surface tension of the wetting liquid, $\theta$ is the contact angle of the wetting liquid and $p$ is differential pressure. ${ }^{37-39}$ The pores of the nanofibre mat were filled with a wetting liquid, and the liquid was removed by pressurized $\mathrm{N}_{2}$ gas allowed to flow
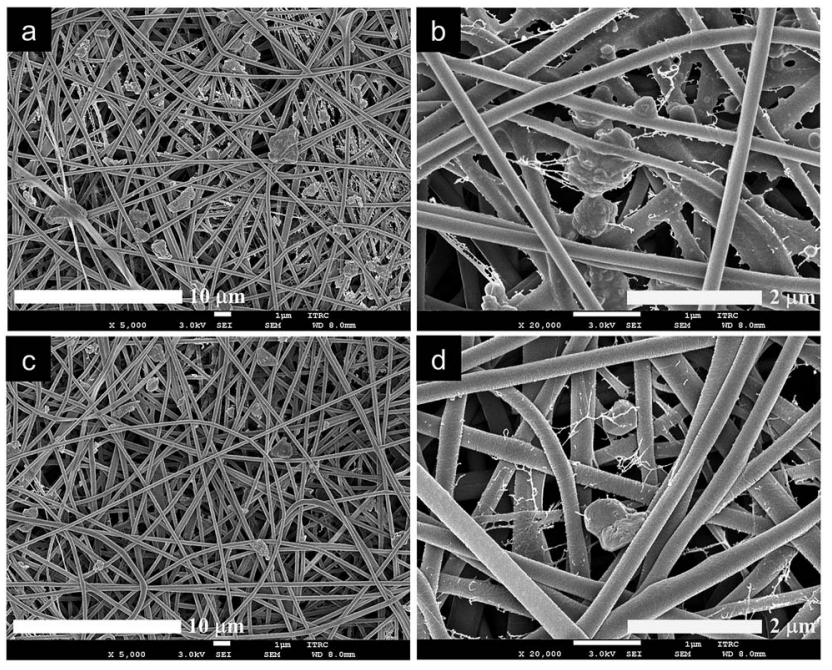

Fig. 4 Morphology of (a and b) [I]MgO/PANF and (c and d) [I]POM/ PANF nanofibre composites used as inner layers of nanofibrous protective materials. 


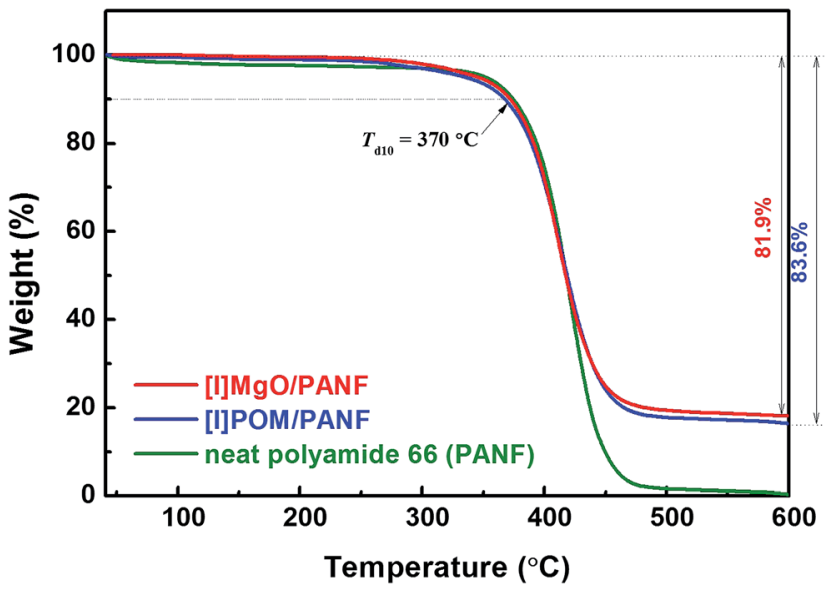

Fig. 5 Thermal degradation behavior of neat polyamide 66 nanofibres (PANF), [I]MgO/PANF and [I]POM/PANF nanofibre composites.

through the empty pores. The adsorbents on the nanofibre surface decreased the mean flow pore diameter of $[\mathrm{I}] \mathrm{MgO} / \mathrm{PANF}$ $(0.139 \mu \mathrm{m})$ compared with that of PANF $(0.150 \mu \mathrm{m})$. The pore volume was also decreased by the presence of adsorbent. The smaller flow pore diameter caused the air permeability to decrease, as summarized in Table 2. In the case of WVTR, the composite nanofibre mats [I]MgO/PANF and [I]POM/PANF showed similar water vapor permeability compared with that of neat PANF. These results indicate that the decrease of flow pore diameter influences the air permeability more than the water vapor permeability of the composite nanofibre mats. These results indicate that the nanofibre composites should be able to improve the problem of moisture retention affecting the protective clothing currently used by the Korean Army.

To investigate the resistance of the composite nanofibre mats to permeation by gas CWAs, permeation tests were conducted using the simulants 2-CEES and DMMP. Table 3 shows the relative amounts of the simulants that penetrated through PANF, [I]MgO/PANF and [I]POM/PANF. The composite nanofibre mats showed slightly better performance than PANF, but were not sufficiently effective to protect users from the CWAs. A single sheet of the composite nanofibre mat ( $91 \mu \mathrm{m}$ thick) was ineffective to adsorb the passing simulant gas. On closer scrutiny, in the direct contact-type experiments (see Fig. S3†), the simulant gas passed directly through the nanofibre mat, so the captured amount of simulant was larger than that in the dynamic diffusion-type experiments regardless of the small amount of simulant gas that passed through the mat $\left(1000 \mathrm{~cm}^{3}\right.$ vs. $2000 \mathrm{~cm}^{3}$ ). In addition, 2-CEES penetrated into the nanofibre mats more than DMMP. This is attributed to the higher volatility of 2-CEES than DMMP. Because a single layer of the composite nanofibre mats would not effectively protect a user from CWAs, we decided to use several sheets of the composite nanofibre mats as the inner layer of materials to achieve acceptable protection against CWAs.

\section{Assembly of outer and inner layers to form nanofibrous protective materials against CWA simulants}

The numbers of outer and inner layers were coordinated to compare the protection ability of the assemblies against CWAs according to thickness. Also, to compare the effectiveness of the adsorbents ( $\mathrm{MgO}$ and $\mathrm{POM}$ ), outer and inner layers containing the same adsorbent were paired. In particular, it was desired that the outer layer based on mANF should contain at least two layers because $m$ ANF aligned in the same direction. The $m$ ANF mats showed excellent mechanical properties along the alignment direction, but not along the transverse direction. Controlling the layer stacking allowed the overall performance of the assemblies to be regulated. The repellent nature of the outer layers prevents invasion of the assemblies by the liquid CWA. Meanwhile, the adsorbents in the inner layers are expected to restrain penetration of gas CWAs.

Physical properties, such as thickness, weight per area, cool/ warm feeling and air/moisture permeability, of each assembly were compared with those of the permeable protective clothing of the Korean Army that is currently being used as chemical protective gear as a reference. The physical properties of each assembly strongly depended on the number of stacked layers, which allowed the desired properties of the assemblies to be improved by layer stacking. As listed in Table 4, the thickness and weight per area of the assemblies increased with layer number. In the case of the assembly composed of two outer layers and six inner layers, the thickness and weight of the assembly were similar to those of the reference material. Therefore, to lighten the weight of the assemblies compared with that of currently used permeable protective clothing, the number of layers in the assemblies was limited to a maximum of eight.

The cool/warm feeling of a material can be evaluated by $q_{\text {max }}$. $\mathrm{Cool} /$ warm feeling represents the transfer of heat from a body to a sample of lower temperature. The magnitude of heat transferred after $0.2 \mathrm{~s}$ from the moment the sample contacts with the heated body was converted to $q_{\max }$, which may increase or decrease depending on the sample. If $q_{\max }$ increases, it indicates that the material feels cold and vice versa. Table 4 lists $q_{\max }$ of the assemblies with various thicknesses. There was little difference between $q_{\text {max }}$ of assemblies containing $\mathrm{MgO}$ and POM with the same thickness. The cool feeling of the assemblies decreased as their thickness increased with raising layer

Table 2 Air permeability and water vapor transmittance rate of inner layers

\begin{tabular}{lccc}
\hline Material & PANF & [I]MgO/PANF & [I]POM/PANF \\
\hline Air permeability $^{a}(\mathrm{cfm})$ & $0.358 \pm 0.008$ & $0.306 \pm 0.004$ & $0.261 \pm 0.020$ \\
Water vapor transmission rate $^{b}\left(\mathrm{~g}\right.$ per $\mathrm{m}^{2}$ per day $)$ & $4863 \pm 101$ & $4575 \pm 35$
\end{tabular}

${ }^{a}$ ASTM D737, test pressure $125 \mathrm{~Pa}$, test area $38 \mathrm{~cm}^{2} .{ }^{b}$ ASTM E96, 40\% RH, $40 \pm 1{ }^{\circ} \mathrm{C}$. 
Table 3 Permeation test of the simulant of chemical warfare agents through the inner layer

\begin{tabular}{|c|c|c|c|c|}
\hline CWA simulant & Blank & PANF & {$[\mathrm{I}] \mathrm{MgO} / \mathrm{PANF}$} & [I]POM/PANF \\
\hline \multicolumn{5}{|l|}{ Direct contact } \\
\hline 2 -CEES $\left(\mu \mathrm{g} \mathrm{m}^{-3}\right)$ & $40.14,100 \%$ & $25.88,64.5 \%$ & $12.97,32.3 \%$ & $10.65,26.5 \%$ \\
\hline \multicolumn{5}{|l|}{ Dynamic diffusion } \\
\hline 2-CEES $\left(\mu \mathrm{g} \mathrm{m}^{-3}\right)$ & $30.96,100 \%$ & $6.56,21.2 \%$ & $2.56,8.3 \%$ & $2.02,6.5 \%$ \\
\hline
\end{tabular}

Table 4 Weight, thickness and maximum heat transfer rate $\left(q_{\max }\right)$ of assemblies

\begin{tabular}{|c|c|c|c|c|c|c|c|}
\hline & \multicolumn{4}{|c|}{ Nanofibrous outer/inner layers with $\mathrm{MgO}$ or POM } & \multicolumn{3}{|c|}{$\begin{array}{l}\text { Outer/inner layers of permeable protective clothing } \\
\text { used by the Korean Army }\end{array}$} \\
\hline & $\begin{array}{l}\text { Number of } \\
\text { sheets }\end{array}$ & $\begin{array}{l}\text { Thickness } \\
(\mu \mathrm{m})\end{array}$ & $\begin{array}{l}\text { Weight per } \\
\text { area }\left(\mathrm{g} \mathrm{m}^{-2}\right)\end{array}$ & $\begin{array}{l}\text { Maximum heat } \\
\text { transfer rate, } q_{\max } \\
\left.(\mathrm{W} \mathrm{cm})^{-2}\right)\end{array}$ & $\begin{array}{l}\text { Thickness } \\
(\mu \mathrm{m})\end{array}$ & $\begin{array}{l}\text { Weight per area } \\
\left(\mathrm{g} \mathrm{m}^{-2}\right)\end{array}$ & $\begin{array}{l}\text { Maximum heat } \\
\text { transfer rate, } q_{\max } \\
\left(\mathrm{W} \mathrm{cm}^{-2}\right)\end{array}$ \\
\hline Outer layer $(\mathrm{O})$ & 1 & 75 & 33 & 0.126 & 0.380 & 260 & 0.161 \\
\hline & 2 & 166 & 125 & 0.143 & & & \\
\hline \multirow{4}{*}{ Assembly (O + I) } & $2 \mathrm{O}+2 \mathrm{I}$ & 415 & 285 & 0.124 & 1700 & 620 & 0.087 \\
\hline & $2 \mathrm{O}+4 \mathrm{I}$ & 542 & 423 & 0.121 & & & \\
\hline & $2 \mathrm{O}+6 \mathrm{I}$ & 681 & 581 & 0.116 & & & \\
\hline & $2 \mathrm{O}+8 \mathrm{I}$ & 817 & 653 & 0.110 & & & \\
\hline
\end{tabular}

number. However, the nanofibrous materials gave a cooler feeling than reference material O-KA according to comparison of $q_{\text {max }}$ of O-KA $\left(0.154 \mathrm{~W} \mathrm{~cm}^{-2}\right)$ with those of single sheets of outer/inner layer and the assembly with two outer and two inner layers, which was even thicker than O-KA. This indicates that heat transfers rapidly from the nanofibres to a solid. The assembly composed of two outer and six inner layers showed a cooler feeling compared with that of currently used permeable protective clothing. The inner layer of the reference clothing (IKA) had a great effect on cool/warm feeling than the outer layer because I-KA was formed of a thick polyurethane foam (1.3 $\mathrm{mm}$ ), which contained a considerable amount of air. These results show that the assemblies made of the composite nanofibre mats should feel cooler to wear than the currently used protective clothing.

To estimate the gas transfer through the protective clothing materials, the air and water vapor permeability of assemblies with different compositions and thicknesses were compared with those of currently used permeable protective clothing (Table 5). The reference protective clothing showed the higher air permeability than the assemblies, because the outer layer was made of a woven fabric with warp and weft threads, and the inner layer was made of porous polyurethane foam. In contrast, the assemblies consisted of nonwoven nanofibre mats, so they exhibited extremely low air permeability of less than $0.5 \mathrm{cfm}$. The nanofibre mats in the assemblies have a small fibre diameter of less than $300 \mathrm{~nm}$ and pores with a mean flow pore size of $140 \mathrm{~nm}$. An interesting complicating factor in the analysis of air permeability through the assemblies occurs when the mean free path of air becomes comparable to the fibre size. ${ }^{40}$ Because of air spin at the nanofibre surface, the normal linear dependence of air permeability with pressure drop is less applicable to the air flow field in pores. The pressure drop predicted by assuming continuous flow through beds of fibres is lowered by a one third for a fibre with a diameter of $100 \mathrm{~nm} .{ }^{\mathbf{4 1}}$ However, regarding water vapor transport, although the assemblies showed low air permeability, they exhibited excellent water vapor transport. In particular, the assemblies composed of two outer and six inner layers had similar water vapor permeability to the reference protective clothing. The water vapor permeability of the assemblies consisting of two outer and eight inner layers or more was much lower than that of the reference clothing. Based on the results of the air and water vapor permeability measurements, the assemblies should provide good resistance to the penetration of CWAs in gas form while still allowing water vapor transmission to promote evaporative cooling of the body. The composite nanofibre mats have a porous structure with a mean flow pore diameter of about $140 \mathrm{~nm}$. Their resistance to air flow is quite large because of the small diameter of the flow pores in the assemblies. However, the high resistance to air flow does not impede the diffusion of moisture through the pore structure of the nanofibre mat. These results suggest that the assemblies are promising candidates for protective clothing materials because of their high rates of water vapor transmission and low air flow.

Based on the results of the air and water vapor permeability measurements, the assemblies should provide good resistance to the penetration of CWAs in gas form while still allowing water 
Table 5 Air permeability and water vapor transmission of assemblies

\begin{tabular}{|c|c|c|c|c|c|c|c|}
\hline & \multirow[b]{2}{*}{$\begin{array}{l}\text { Number of } \\
\text { sheets }\end{array}$} & \multicolumn{2}{|c|}{$\begin{array}{l}\text { MgO-containing outer or inner } \\
\text { layers }\end{array}$} & \multicolumn{2}{|c|}{$\begin{array}{l}\text { POM-containing outer or inner } \\
\text { layers }\end{array}$} & \multicolumn{2}{|c|}{$\begin{array}{l}\text { Permeable protective clothing used } \\
\text { by the Korean Army }\end{array}$} \\
\hline & & $\begin{array}{l}\text { Air } \\
\text { permeability } \\
(\mathrm{cfm})\end{array}$ & $\begin{array}{l}\text { Water vapor } \\
\text { transmission } \\
\left(\mathrm{g} \text { per } \mathrm{m}^{2} \text { per } 24 \mathrm{~h}\right)\end{array}$ & $\begin{array}{l}\text { Air } \\
\text { permeability } \\
(\mathrm{cfm})\end{array}$ & $\begin{array}{l}\text { Water vapor } \\
\text { transmission } \\
\left(\mathrm{g} \text { per } \mathrm{m}^{2} \text { per } 24 \mathrm{~h}\right)\end{array}$ & $\begin{array}{l}\text { Air } \\
\text { permeability } \\
(\mathrm{cfm})\end{array}$ & $\begin{array}{l}\text { Water vapor } \\
\text { transmission } \\
\left(\mathrm{g} \text { per } \mathrm{m}^{2} \text { per } 24 \mathrm{~h}\right)\end{array}$ \\
\hline \multirow[t]{2}{*}{ Outer layer $(\mathrm{O})$} & 1 & 0.534 & 4809 & 0.503 & 4675 & 5.41 & 4342 \\
\hline & 2 & 0.272 & 4748 & 0.267 & 4480 & & \\
\hline \multirow[t]{2}{*}{ Inner layer (I) } & 1 & 0.261 & 4575 & 0.306 & 4722 & 60.7 & 3623 \\
\hline & 2 & 0.126 & 4282 & 0.152 & 4331 & & \\
\hline \multirow[t]{4}{*}{ Assembly $(\mathrm{O}+\mathrm{I})$} & $2 \mathrm{O}+2 \mathrm{I}$ & 0.062 & 4062 & 0.068 & 4229 & 4.27 & 3292 \\
\hline & $2 \mathrm{O}+4 \mathrm{I}$ & 0.057 & 3662 & 0.064 & 3809 & & \\
\hline & $2 \mathrm{O}+6 \mathrm{I}$ & 0.032 & 3229 & 0.036 & 3494 & & \\
\hline & $2 \mathrm{O}+8 \mathrm{I}$ & 0.026 & 2188 & 0.030 & 2276 & & \\
\hline
\end{tabular}

vapor transmission to promote evaporative cooling of the body. The composite nanofibre mats have a porous structure with a mean flow pore diameter of about $140 \mathrm{~nm}$. Their resistance to air flow is quite large because of the small diameter of the flow pores in the assemblies. However, the high resistance to air flow does not impede the diffusion of moisture through the pore structure of the nanofibre mat. These results suggest that the assemblies are promising candidates for protective clothing materials because of their high rates of water vapor transmission and low air flow.

To estimate the protective performance of the assemblies against liquid CWAs, their surface wettability was evaluated using WCA and OCA measurements with water, 2-CEES and DMMP. The surface wettability of the outer layer of the reference protective clothing O-KA was measured in the same way for comparison with that of the assemblies. The samples possessed an amphiphobic nature, as shown in Fig. 6. O-KA displayed both hydrophobicity with a WCA higher than $120^{\circ}$ and oleophobicity. The assemblies simultaneously exhibited superhydrophobicity (WCA greater than $150^{\circ}$ ) and high oleophobicity (OCA higher than $120^{\circ}$ ). We believe that the difference of wettability between the assemblies and O-KA can be attributed to the surface roughness of the samples. ${ }^{34}$ The outer layer of each assembly contained the adsorbents $\mathrm{MgO}$ and POM on the surface of nanofibres and nanofibre mats, so it had a rougher surface than that of O-KA. The increase of surface roughness was essential to develop non-wettable surfaces. The increase of roughness induced by the adsorbents improved the ability of the assembly to protect against CWA simulants.

To investigate the resistance of the assemblies to permeation by gas CWAs, permeation tests were conducted according to the TOP 08-2-501 standard using the simulants 2-CEES and DMMP. The penetration behavior of the simulants through each assembly was profiled by measuring the amount of simulant
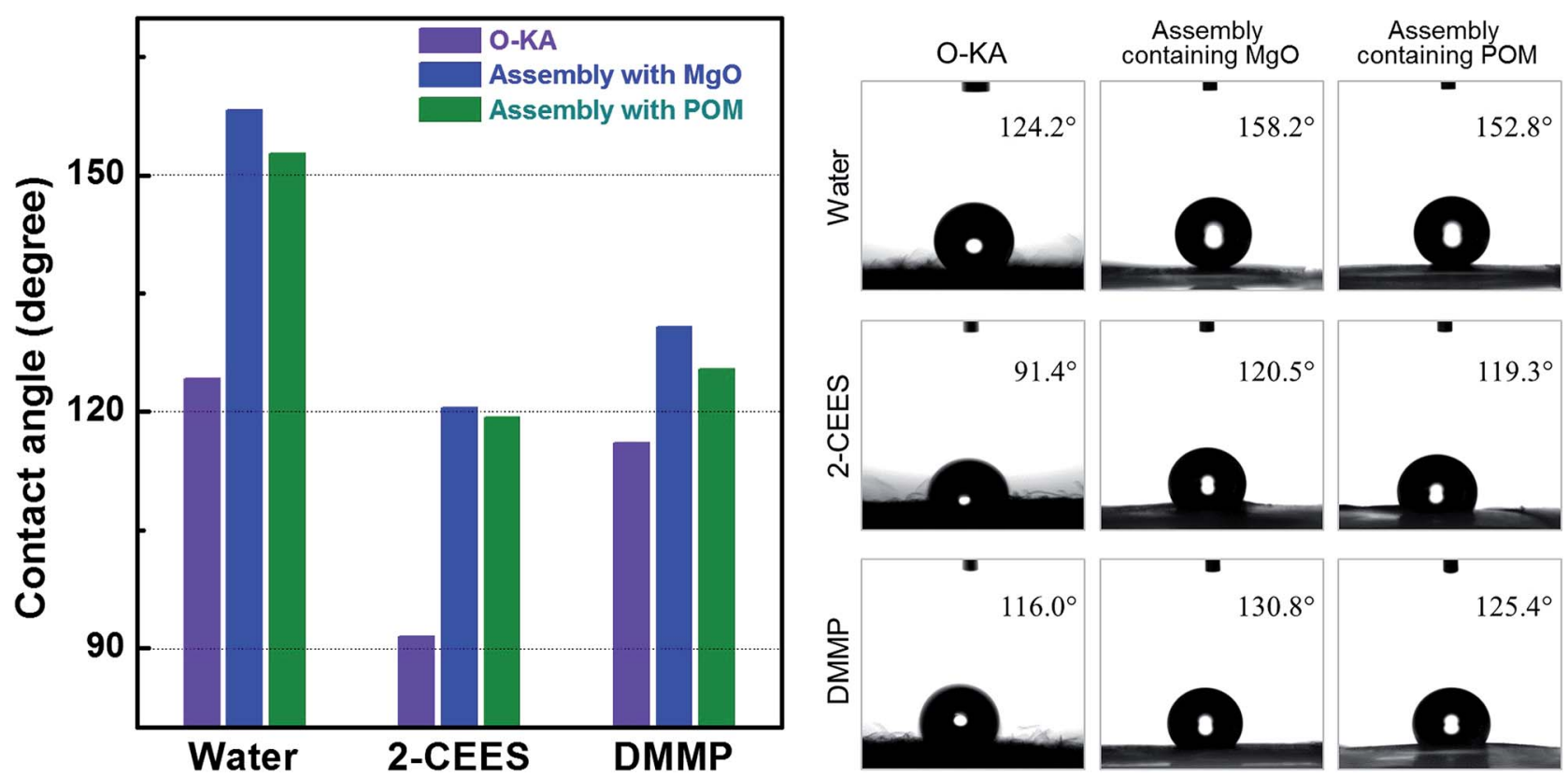

Fig. 6 Amphiphobic surface behavior of the outer layer of permeable protective clothing used by the Korean Army (O-KA), and assemblies containing $\mathrm{MgO}$ and POM as nanofibrous protective materials against CWA simulants 2-CEES and DMMP. 


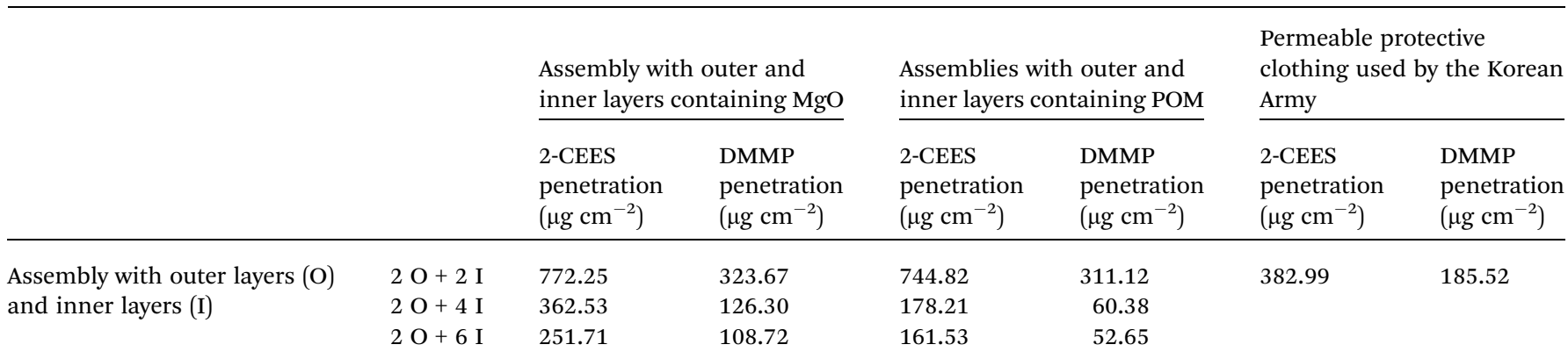

that passed through the assembly at regular intervals, as shown in Fig. S10. $\dagger$ Evaporated 2-CEES gas rapidly passed through the assembly and all of the gas had penetrated though the assembly after $6 \mathrm{~h}$ room temperature. In the case of DMMP, the gas passed slowly and continuously through the sample for $12 \mathrm{~h}$. These results were attributed to the difference in volatility between 2CEES and DMMP; 2-CEES shows much higher relative volatility $\left(<3.4 \mathrm{mmHg}\right.$ vapor pressure at $25^{\circ} \mathrm{C}, 16570 \mathrm{mg} \mathrm{m}^{-3}$ volatility at $\left.20{ }^{\circ} \mathrm{C}\right)$ than DMMP $\left(\sim 1 \mathrm{mmHg}\right.$ vapor pressure at $25^{\circ} \mathrm{C}, 347 \mathrm{mg}$ $\mathrm{m}^{-3}$ volatility at $20{ }^{\circ} \mathrm{C}$ ). The penetration behavior of simulants was similar for the assemblies with POM and the reference protective clothing (data not shown). Table 6 lists the relative amounts of the simulants that penetrated through the reference protective clothing and assemblies with $\mathrm{MgO}$ and POM. The assembly with two outer and eight inner sheets was excluded from the evaluation because it showed poorer performance in terms of weight density and moisture permeability than the reference material. The reference protective clothing currently used by the Korean Army exhibited permeabilities of $383 \mu \mathrm{g}$ $\mathrm{cm}^{-2}$ for 2-CEES and $186 \mu \mathrm{g} \mathrm{cm}{ }^{-2}$ for DMMP after $12 \mathrm{~h}$. These results are similar to those obtained for the assembly containing $\mathrm{MgO}$ with two outer and four inner sheets, indicating that the assembly had a comparable level of protection ability to the protective clothing despite its thinner thickness and lighter weight. In addition, the assembly exhibited better moisture permeability and cool/warm feeling than the reference protective clothing. The assembly containing POM with two outer and four inner sheets showed higher protection ability than the reference protective clothing. These results indicate that the assemblies based on nanofibrous composites can be used to make lighter protective clothing materials than those currently available. Furthermore, the assembly with two outer and six inner sheets, which had comparable weight density to that of the reference protective clothing, exhibited improved protection ability against the simulants. This means that although only one layer of nanofibrous material does not achieve protection ability, assemblies of laminated nanofibre layers can attain more effective protection against CWAs than the currently used permeable protective clothing.

\section{Conclusions}

The objective of this study was to develop permeable nanofibrous materials for used as protective clothing against CWAs.
To prevent the invasion of liquid CWAs, amphiphobic nanofibre composites were applied as outer layers. The outer layers were not wetted by water, 2-CEES and DMMP. Inner layers, designed to adsorb gaseous CWAs, showed better adsorption of CWA simulants than that of a neat PANF, but the use of a single layer was inadequate to protect from CWAs. Therefore, assemblies, composed of several sheets of outer and inner layers, were fabricated by a spray- and heat-bonding process in order to improve the protection ability of the inner layers against CWAs. The properties of the assemblies, such as thickness, weight density, air/moisture permeability, cool/warm feeling and protection ability, can be controlled by the number of stacked sheets. As a result, the assemblies can provide good protection against CWAs, while still allowing considerable water vapor transmission to promote evaporative cooling of the body. These assemblies can be used as a protective material against various contaminants such as organic pollutants and harmful particulates, as well as against CWAs. Our results will enable the design and production of permeable protective clothing with superior performance to that currently available.

\section{Acknowledgements}

This research was supported by the Defense Acquisition Program Administration (DAPA) and by the Agency for Defense Development (ADD).

\section{Notes and references}

1 NATO Handbook on the Medical Aspects of NBC Defensive Operations, Department of the Army, Washington, DC, 1996.

2 L. Szinicz, Toxicology, 2005, 214, 167.

3 E. F. G. Dickson, J. Toxicol. Environ. Health, Part A, 2008, 71, 1382.

4 P. Gao, W. P. King and R. J. Shaffer, J. Occup. Environ. Hyg., 2007, 4, 562 .

5 T. Pal, G. D. Griffin, G. H. Miller, A. P. Watson, M. L. Daugherty and T. Vodinh, J. Hazard. Mater., 1993, 33, 123.

6 D. K. Liu, R. W. Wannemacher, T. H. Snider and T. L. Hayes, J. Appl. Toxicol., 1999, 17, S41.

7 E. Wilusz, Military Textiles, Woodhead Publishing Limited, England, 2008. 
8 S. Sundarrajan and S. Ramakrishna, J. Mater. Sci., 2007, 42, 8400.

9 G. W. Wagner, P. W. Bartram, O. Koper and K. J. Klabunde, J. Phys. Chem. B, 1999, 103, 3225.

10 T. H. Mahato, G. K. Prasad, B. Singh, K. Batra and K. Ganesan, Microporous Mesoporous Mater., 2010, 132, 15.

11 T. H. Mahato, G. K. Prasad, B. Singh, J. Acharya, A. R. Srivastava and R. Vijayaraghavan, J. Hazard. Mater., 2009, 165, 928.

12 G. K. Prasad, T. H. Mahato, B. Singh, K. Ganesan, P. Pandey and K. Sekhar, J. Hazard. Mater., 2007, 149, 460.

13 D. A. Panayotov and J. R. Morris, J. Phys. Chem. C, 2009, 113, 15684.

14 R. Ramaseshan and S. Ramakrishna, J. Am. Ceram. Soc., 2007, 90, 1836.

15 Ş. Neaţu, V. I. Pârvulescu, G. Epure, N. Petrea, V. Şomoghi, G. Ricchiardi, S. Bordiga and A. Zecchina, Appl. Catal., B, 2009, 91, 546.

16 M. Grandcolas, L. Sinault, F. Mosset, A. Louvet, N. Keller and V. Kellera, Appl. Catal., A, 2011, 391, 455.

17 B. Cojocaru, Ş. Neaţu, V. I. Pârvulescu, V. Şomoghi, N. Petrea, G. Epure, M. Alvaro and H. Garcia, ChemSusChem, 2009, 2, 427.

18 Ş. Neaţu, B. Cojocaru, V. I. Pârvulescu, V. Şomoghi, M. Alvaro and H. Garcia, J. Mater. Chem., 2010, 20, 4050.

19 B. M. Smith, Chem. Soc. Rev., 2008, 37, 470.

20 O. Koper, E. Lucas and K. J. Klabunde, J. Appl. Toxicol., 1999, 19, S59.

21 M. K. Ferguson-McPherson, E. R. Low, A. R. Esker and J. R. Morris, Langmuir, 2005, 21, 11226.

22 N. M. Okun, J. C. Tarr, D. A. Hilleshiem, L. Zhang, K. I. Hardcastle and C. L. Hill, J. Mol. Catal. A: Chem., 2006, 246, 11.

23 R. D. Gall, C. L. Hill and J. E. Walker, J. Catal., 1996, 159, 473.

24 S. Agarwal, A. Greiner and J. H. Wendorff, Prog. Polym. Sci., 2013, 38, 963.

25 J.-M. Li, D.-P. Wei, Y.-B. Hu, F. Jie and Z.-A. Xu, CrystEngComm, 2014, 16, 964.
26 J.-M. Li, X.-L. Zeng, D.-P. Wei, Y.-B. Hu and Z.-A. Xu, ACS Appl. Mater. Interfaces, 2014, 6, 4490.

27 R. Ramaseshan, S. Sundarrajan, Y. Liu, R. S. Barhate, N. L. Lala and S. Ramakrishna, Nanotechnology, 2006, 17, 2947.

28 H. L. Schreuder, P. Gibson, K. Senecal, M. Sennett, J. Walker, W. Yeomans, D. Ziegler and P. T. Tsai, J. Adv. Mater., 2002, 34, 44.

29 ASTM D5160-95, Standard Guide for Gas-Phase Adsorption Testing of Activated Carbon, American Society for Testing and Materials (ASTM) International, West Conshohocken, 2008.

30 S.-Y. Ryu, J. W. Chung and S.-Y. Kwak, Compos. Sci. Technol., 2015, 117, 9.

31 M. Yoneda and S. Kawabata, J. Text. Mach. Soc. Jpn., 1985, 31, 79.

32 Test Operations Procedure 8-2-501, Permeation and Penetration of Air-permeable, Semipermeable and Impermeable Materials with Chemical Agents or Simulants (Specimen Testing), U.S. Army Dugway Proving Ground, UT, March 1997, unclassified report AD A322329.

33 H. Y. Erbil, Surface Chemistry of Solid and Liquid Interfaces, Wiley-Blackwell, Oxford, 2006.

34 J. Zhao, C. Dai, J. Fang, X. Feng, L. Yan and M. Zhao, Colloids Surf., A, 2014, 448, 93.

35 S. Sundarrajan and S. Ramakrishna, J. Mater. Sci., 2007, 42, 8400 .

36 Y. Ding, P. Zhang, Y. Jiang, F. Xu, J. Yin and Y. Zuo, Mater. Lett., 2009, 63, 34.

37 A. Jena and K. Gupta, A Novel Technique for Pore Structure Characterization Without the Use of Any Toxic Material, Nondestructive Characterization of Materials XI, Springer, New York, 2002.

38 A. Jena and K. Gupta, Fluid/Part. Sep. J., 2002, 14, 227.

39 A. Jena and K. Gupta, J. Power Sources, 1999, 80, 46.

40 A. A. Kirsch, I. B. Stechkina and N. A. Fuchs, Aerosol Sci., 1974, 5, 39.

41 W. Hinds, Aerosol Technology, Wiley, New York, 1982. 